\title{
Başarısız endoprotez uygulamalarında revizyon cerrahisi
}

\author{
Revision surgery for failed endoprosthesis
}

\author{
Enes Uluyardımcı ${ }^{1}$, Mehmet Asiltürk ${ }^{2}$, Çetin Işı $\left.\right|^{3}$ \\ 1'Develi Hatice-Muammer Kocatürk Devlet Hastanesi, Ortopedi ve Travmatoloji Kliniği, Develi, Kayseri \\ ${ }^{2}$ Ankara Şehir Hastanesi, Ortopedi ve Travmatoloji Kliniği, Çankaya, Ankara \\ ${ }^{3}$ Memorial Ataşehir Hastanesi, Ortopedi ve Travmatoloji Kliniği, Ataşehir, İstanbul
}

\begin{abstract}
Yaşlılarda kalça kırı̆̆ı tedavisinde endoprotez uygulamaları sıkça kullanılan tedavi yöntemlerindendir. Ortalama yaşam süresinde artmaya bağlı olarak ileri yaş hasta grubunda kalça kırığı sayısında ve bununla birlikte revizyon endoprotez cerrahisi gereksiniminde artış beklenmektedir. Endoprotez uygulamaları sonrası en sık başarısızık nedenleri; ağrı, instabilite, enfeksiyon ve periprostetik kırık olarak gösterilmektedir. Başarısız endoprotez uygulamasının yönetiminde başlangıç noktası, etiyolojiyi doğru tespit etmek olmalıdır. Sistematik bir değerlendirme ile problemin kaynağı tespit edilmeli ve buna yönelik tedavi planlanmalıdır. Başarısız endoprotezin standart tedavisi total kalça protezine dönüştürme olmakla birlikte etiyolojiye özgü diğer tedavi seçenekleri de akılda tutulmalıdır. Bu özel yaş grubunda çoğu kez eşlik eden sistemik hastalıkların varlığı ve azalmış kemik kalitesi revizyon cerrahisini güçleştirmektedir. Revizyon cerrahisinin komplikasyon oranları yüksek olsa da ayrıntılı ameliyat öncesi planlama ve cerrahi deneyim ile komplikasyon oranları azaltılarak tedavi neticesinde temel amaç olan hastanın en kısa sürede hareketini kazanması ve önceki aktivite seviyesine ulaşması başarılabilir.
\end{abstract}

Anahtar sözcükler: endoprotez; hemiartroplasti; komplikasyon; revizyon

\begin{abstract}
The application of endoprosthesis is a frequently used treatment method in the treatment of hip fractures in the elderly. The number of hip fractures in the advanced age patient group has increased associated with the increase in mean life expectancy, and there is therefore expected to be an increase in the need for revision endoprosthesis surgery. The most frequent reasons for failure after endoprosthesis application are pain, instability, infection and periprosthetic fracture. The starting point for the management of failed endoprosthesis application should be the correct determination of the etiology. The source of the problem should be determined with a systematic evaluation, and treatment should be planned according to this. Although the standard treatment for failed endoprosthesis is to convert it to total hip prosthesis, it should be kept in mind that there are other treatment options specific to the etiology. That there are usually comorbid systemic diseases and reduced bone quality in this particular age group make revision surgery more difficult. Although complication rates of revision surgery are high, with detailed preoperative planning and an experienced surgeon, complication rates can be reduced, and success can be achieved in mobilising the patient in a short time, which is a basic aim of the treatment, and reaching the previous level of activity.
\end{abstract}

Key words: endoprosthesis; hemiarthroplasty; complication; revision

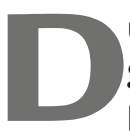

ünyada ve ülkemizde ortalama yaşam süresi gittikçe artmakta ve bunun neticesinde yaşlı popülasyonda kalça kırıkları sayısında da artış gözlenmektedir. Önümüzdeki iki dekatta yaşlılarda kalça kırığı sayısının iki katına, 2050 yılında ise üç katına çıkacağı öngörülmektedir. ${ }^{[1]}$ Tıbbi ek hastalıklara sahip bu yaş grubunda kalça kırıklarının yönetimi ortopedi ve travmatoloji alanındaki cerrahinin zorlu alanlarından biri olarak görünmektedir. Bu kırıklarda çeşitli internal tespit yöntemleri, parsiyel endoprotez ve total kalça protezi uygulamaları tedavi seçeneklerini oluşturmaktadır. Internal tespit sonrası yüksek oranda revizyon cerrahisi gereksinimi ${ }^{[2]}$ sebebiyle yaşlılarda kalça kırıklarının tedavisinde endoprotez uygulaması oldukça kabul gören bir cerrahi yöntem olmuştur. ${ }^{[3,4]}$ Endoprotez, ileri yaş grubu hastalarda mortalite ve morbiditeyi azaltmaktadır, ancak endoprotez cerrahisi de çeşitli komplikasyonlarla ilişkilidir. ${ }^{[5]}$ Endoprotez sonrası \%4-24

\footnotetext{
- İletişim adresi: Op. Dr. Enes Uluyardımcı, Develi Hatice-Muammer Kocatürk Devlet Hastanesi, Ortopedi ve Travmatoloji Kliniği, Develi, Kayseri Tel: 0532 - 0663263 e-posta: enesuluyardmc7@hotmail.com
} 
arası revizyon ihtiyacı bildirilmiştir. ${ }^{[6,7]}$ Endoprotez uygulamalarında başarısızığın en sık nedenleri olarak ağrı, instabilite, enfeksiyon ve periprostetik kırık sıralanabilir. ${ }^{[5]}$ Bu komplikasyonlar mortaliteyi, morbiditeyi ve maliyetleri artırmaktadır. ${ }^{[8]} \mathrm{Bu}$ komplikasyonların başarılı yönetimi oldukça zorlayıcı olup ciddi bir cerrahi tecrübeyi gerektirmektedir. Bu bölümde başarısız endoprotez cerrahisinin nedenleri ve bu nedenlerin yönetimi üzerinde durulacaktır.

\section{ETIYOLOJi}

Endoprotez uygulamaları sonrası en sık başarısızlık nedenleri; ağrı, instabilite, enfeksiyon ve periprostetik kırık olarak sıralanmaktadır. ${ }^{[5]}$ Başarısız endoprotez cerrahisi için erkek cinsiyet, 75 yaş altı olmak, şizofreni ve son dönem renal hastalık önemli risk faktörleri olarak bildirilmiştir. ${ }^{[9,10]}$

\section{Ağrı}

Endoprotez sonrası ağıının araştırılması karmaşık bir süreç olsa da doğru şekilde sorgulandığında tanı hakkında ciddi ipuçları elde edilebilir. Öncelikle ağrının kalça sebepli mi yoksa kalça dışı sebepli mi olduğu araştırılmalıdır. Kalça ekleminde spinal (omurga) kaynaklı ağrıyla azımsanmayacak kadar çok sıklıkta karşılaşılmaktadır. Kalça eklemine lokal anestezi enjeksiyonu ile spinal kaynaklı ağrılar dışlanabilir. Ayrıca uygun olmayan femoral offset nedeniyle trokanterik bursit gelişebilir. Zorlu abduksiyon ile şiddetlenen yan (lateral) kalça ağrısı trokanterik bursite işaret edebilir.

Ağrının yeri, niteliği ve zamanlaması da araştırılmalıdır. Kasık bölgesine sınırlı ağrılar genel olarak asetabular kaynaklı bir patolojiyi düşündürür. Endoprotez sonrası femoral komponent ile eklemleşen doğal asetabulumda zamanla erozyon meydana gelebilir. Bu durum özellikle aktivite seviyesi ve ilk cerrahiden sonra geçen süre ile doğru orantılı olarak daha fazla olup, hareketsiz yaşam tarzı olan hastalarda ise daha az sıklıkta gözlenir. Asetabular aşınma femoral komponent gevşemesine göre sık meydana gelir ve bu durum ilerleyici olabilir. Asetabular aşınma şiddetlenip kalça ekleminde medializasyona sebep olduğunda bu durum protrüzyo asetabuli olarak adlandırılır. ${ }^{[11]}$

Uyluk bölgesine lokalize bir ağrının varlığı femoral komponentin aseptik gevşemesini akla getirmelidir. Aseptik gevşeme femoral komponent seçimi ile ilişkili olabilir. Çimentolu veya çimentosuz femoral stem (komponent) seçimi ile ilgili literatürde fikir birliği yoktur. Lee ve ark., yaptıkları meta-analiz çalışmasının neticesinde çimentolu stemler ile daha az ameliyat sonrası ağrı, daha iyi fonksiyonel sonuç elde edilebileceğini ve çimentolu stemlerin daha az implant ile ilişkili komplikasyonlara sahip olduğunu bildirmişlerdir. ${ }^{[12]}$ Ciddi düzeyde osteoporotik hastalarda kemiksel entegrasyon ve ameliyat içi periprostetik kırık endişesi nedeniyle çimentolu stemler tercih sebebi olabilir. ${ }^{[13]}$ Ancak modern modüler femoral stemler ile bu problemlerin daha az yaşandığı ve modern çimentosuz protezlerle çimentolu protezlere benzer sonuçlar alınabileceği gösterilmiştir. ${ }^{[14]}$ Daha uzun cerrahi süre ve olası çimento reaksiyonu riski düşünülerek ameliyat içi stabilite sağlanabildiğinde yazarlar çimentosuz protezleri ilk seçenek olarak düşünmektedir.

Ani başlangıçlı bir ağıı periprostetik kırığa, komponent kırılmasına veya çıkığa bağı olabilir. İstirahatte olmayıp ilk adımla gelişen ağrı aseptik gevşemeyi akla getirir. illk baştaki (erken dönemde) iyileşmeyi takiben ortaya çıkan sinsi ağıı başlangıcı enfeksiyon ve komponentte gevşemeyi düşündürtebilir. İyileşme veya rahatlama dönemi olmaksızın sürekli ağrı varlığı ise komponentte kötü konumlandırma (malpozisyon) ve enfeksiyon varlığını destekler.

\section{İnstabilite}

Total kalça protezi ile kıyaslandığında endoprotez (parsiyel protez) sırasında daha büyük bir baş kullanılır. Bu durum daha fizyolojiktir ve yüksek atlama mesafesi nedeniyle total kalça protezine göre daha stabil olduğu düşünülür. Ancak endoprotez sonrası \%16’ya varan oranlarda çıkık bildirilmiştir.[15] Çıkık sonrası mortalite birinci ayda \%10, üçüncü ayda \%50 ve altın$\mathrm{Cı}$ ayda ise \%65 olarak yayımlanmıştır. ${ }^{[16]}$ Endoprotez sonrası stabilite; implant seçimi, komponent pozisyonu ve hastaya bağlı faktörlerden etkilenir. ${ }^{[5]}$

Bipolar veya unipolar baş seçimi tartışmalıdır. Bipolar protezlerdeki ek eklemleşmenin stabiliteyi artırabileceği ve asetabular aşınmayı azaltabileceği savunulmaktadır. Ayrıca bipolar sistemlerdeki boyun alternatifleri bacak boyunu eşitlemede avantaj sağlamaktadır. Yine de bipolar protezlerdeki iç katmandaki hareketlilik zamanla azalarak mekanik olarak unipolar başlara benzer hale gelebilmektedir. ${ }^{[17]}$

Stabilite açısından femoral komponent yerleşimi oldukça önemlidir. Femoral komponent, fizyolojik anteversiyonu ve femoral offseti yeniden sağlamış olmalıdır. Varus kötü konumlandırması, uygun olmayan femoral offset ve zayıf kalkar yerleşimi çıkık için risk teşkil eder. [18] Öncesinde asetabular retroversiyona sahip olan hastalarda femoral versiyonun doğru ayarlanamamış olması durumunda ve Wiberg'in merkez-kenar açısı düşük olan hastalarda çıkık riski artmıştır. ${ }^{[19]}$ İnme veya Parkinson gibi kas dengesizliğine neden olan durumların varlığında ve demans veya deliryum gibi bilişsel bozukluğa sahip hastalarda da çıkık riski artmış durumdadır. ${ }^{[20]}$ 


\section{Enfeksiyon}

Endoprotez sonrası enfeksiyon oranları Noailles ve ark. tarafından \%1,7 ve \%7,3 arasında bildirilmiştir. ${ }^{[8]}$ Aynı çalışmada risk faktörleri ameliyat öncesi eşlik eden hastalıklar (obezite, karaciğer fonksiyon bozukluğu, ileri yaş), cerrahiyle ilgili durumlar (cerrahi deneyim, çimentosuz stemler, cerrahiye kadar geçen süre) ve ameliyat sonrasıyla ilgili durumlar (uzamış yatış, hematom, uzamış yara yeri drenajı ve üriner kateterizasyon) olarak sıralanmıştır. Endoprotez sonrası şikâyeti olan tüm hastalarda enfeksiyon varlığından şüphe edilmelidir. Enfeksiyonun dışlanması oldukça zor olsa da Kas-İskelet Enfeksiyon Derneği (MSIS)'nin tanı kriterleri bu konuda oldukça yararlıdır. ${ }^{[21]}$ Buna göre majör kriterler; 1) mikroorganizmanın da izole edildiği iki pozitif kültür sonucu ve 2 ) eklem ile ilişkili sinus traktının (yolunun) varlığıdır. Minör kriterler ise; 1) yükselmiş serum CRP (C-Reaktif Protein) seviyesi ve eritrosit sedimentasyon oranı, 2) sinovyal sıvıda beyaz hücre sayısının artması veya pozitif lökosit esteraz strip test, 3 ) sinovyal sıvıda polimorf nüveli lökosit oranının artması, 4) periprostetik dokunun pozitif histolojik analizi ve 5) pozitif tek kültür sonucudur. Bir majör kriter veya üç minör kriter varlığında periprostetik enfeksiyon olarak değerlendirilmelidir.

\section{Periprostetik Kırık}

Yoon ve ark., çimentosuz endoprotez sonrası yaklaşık iki yıllık takip neticesinde periprostetik kırık oranının \%2,4 olduğunu ve bu kırıkların yaklaşık üçte ikisinin ilk yıl içerisinde gerçekleştiğini bildirmişlerdir. ${ }^{[22]}$ Vancouver sınıflama sistemi, hem kırık sınıflaması hem de tedavi algoritması için yön gösterici olup literatürde kabul görmüştür (Tablo 1). ${ }^{[23]}$

\section{TANI}

Başarısız endoprotez tedavisinde ilk adım anamnez ile başlar. Yukarıda anlatıldığı gibi ağrının kaynağı, yeri, niteliği ve zamanlaması ayrıntılı olarak sorgulanmalıdır. ilk cerrahi sonrasında iyileşme olup olmadığı kilit noktalardan biridir. İnstabilite durumunda ilk çıkığın ne zaman gerçekleştiği, kaç kere olduğu ve nasıl tedavi edildiği öğrenilmelidir. Ayrıca kapalı veya açık redüksiyon sonrasında breys kullanıp kullanmadığı da önemlidir. Hastanın bilişsel durumu, nöromusküler patoloji varlığı ve cerrahi sonrasında önerilere uyup uymadığı not edilmelidir. Enfeksiyon açısından; hastada gece ağrısı, ateş, cerrahi sonrası ağrısız dönem varlığı, yara akıntısı öyküsü, eritem veya yara iyileşme problemleri sorgulanmalıdır.

Fizik muayenede önceki cerrahide kullanılan insizyona, yaranın durumuna, sinus traktı olup olmadığına ve bacak boyu eşitsizliğine dikkat edilmelidir. Ayrıca abduktor mekanizmayı değerlendirebilmek amacıyla mümkünse hastanın yürüyüşü de değerlendirilmelidir.

Cerrahi öncesi laboratuvar testleri tüm hastalarda istenmelidir. Böbrek ve karaciğer fonksiyonlarını da içeren ayrıntılı metabolik değerlendirme yapılmalıdır. Yara iyileşmesi bakımından albümin ve prealbümin değerleri önem arz eder. Tam kan sayımı, eritrosit sedimentasyon oranı ve CRP değerleri istenmeli ve artmış enflamasyon belirteçleri varlığında kalça ponksiyonu yapılmalıdır. Son dönemlerde lökosit esteraz ve alfadefensin testleri önem kazanmıştır.

Pelvis AP (ön-arka), kalça AP (ön-arka) ve çapraz masa (cross table) lateral radyografiler rutin olarak elde edilmelidir. Asetabular aşınma, kırık veya anormal versiyon şüphesinde Judet grafileri ve üç boyutlu bilgisayarlı tomografi yardımcı olabilir.

Tablo 1. Periprostetik kırıklar için Vancouver sınıflaması ${ }^{[23]}$

\begin{tabular}{|c|c|c|c|}
\hline Tip & Alt tip & Tanımlama & Tedavi \\
\hline \multirow[t]{3}{*}{ A } & & Trokanterik bölge kırıkları & \\
\hline & AG & Trokanter major kırı̆gı & Non-deplase kırıklarda konservatif, deplase kırıklarda AR-iT \\
\hline & $\mathrm{AL}$ & Trokanter minör kırı̆̆ı & Komponentte gevşeme varsa femoral stem revizyonu \\
\hline \multirow[t]{4}{*}{ B } & & Stem çevresi kırıkları & \\
\hline & B1 & Stem tespiti iyi & Plak ile AR-iT \\
\hline & B2 & $\begin{array}{l}\text { Stem gevssemiş ancak proksimal kemik } \\
\text { stoğu yeterli }\end{array}$ & Uzun poroz kaplı çimentosuz femoral stem ile revizyonu \\
\hline & B3 & $\begin{array}{l}\text { Stem gevşemişs ve parçalı kırık ve/veya } \\
\text { zayıf kemik stoğu }\end{array}$ & $\begin{array}{l}\text { Proksimal femoral allogreftle ya da proksimal femur replasmanına izin veren femora } \\
\text { komponent ile revizyonu }\end{array}$ \\
\hline C & & Femoral stemin distalindeki kırıklar & Plak ile AR-iT \\
\hline
\end{tabular}

AR-IT, açık redüksiyon ve internal tespit. 

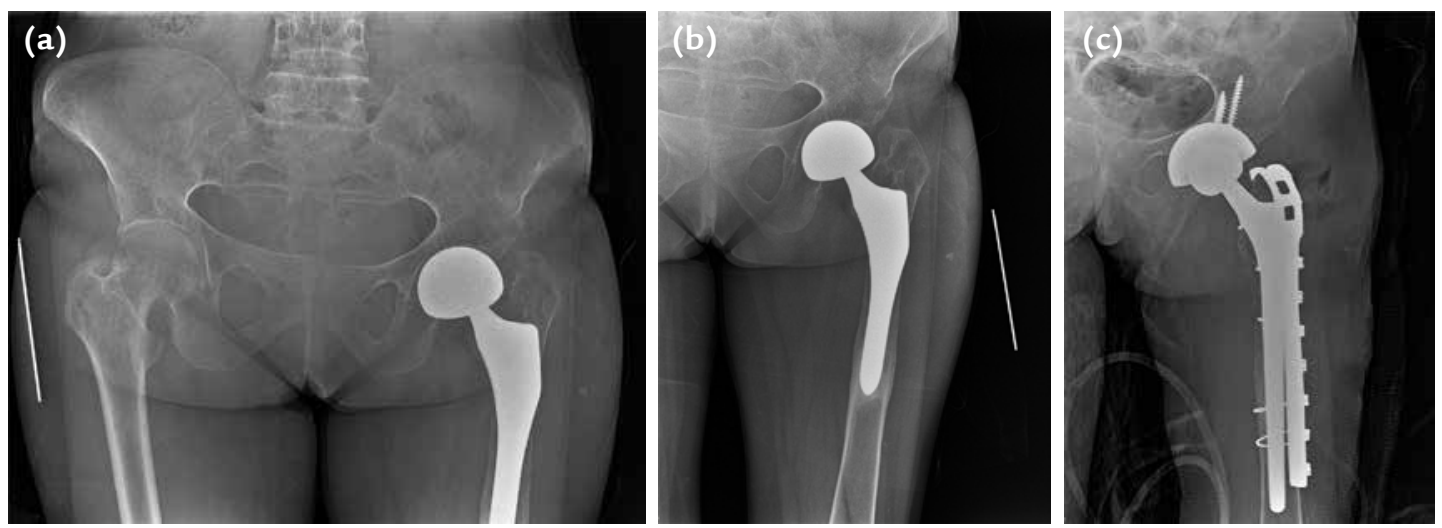

Şekil 1. a-c. Çimentosuz femoral stem etrafında ciddi osteoliz (a, b). Primer çimentosuz asetabular kap, çimentosuz uzun femoral stem ve trokanterik kanca plak ile revize edildi (c).
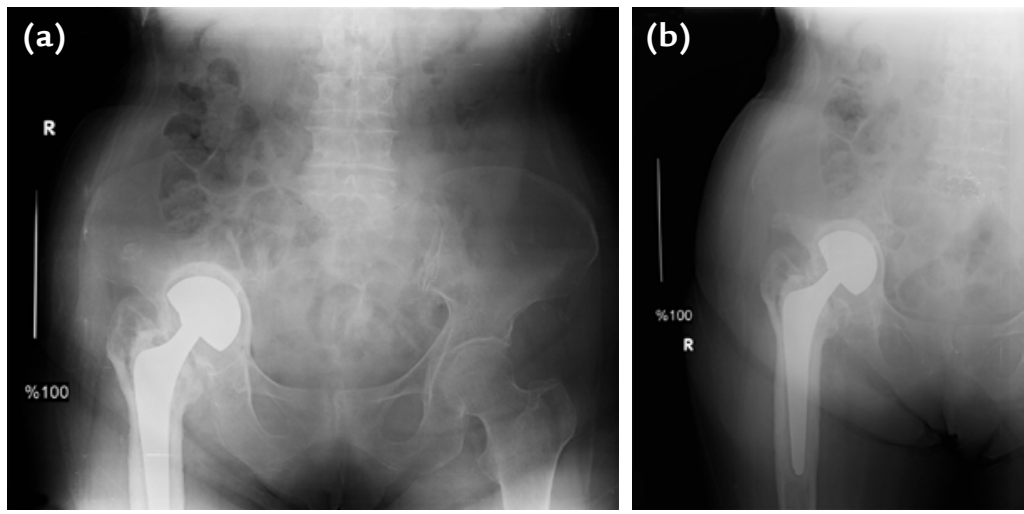

Şekil 2. a-d. İleri asetabular aşınma sonucunda meydana gelen protrüzyo asetabuli (a, b). Femur başı allogrefti ile asetabular çatı desteği sağlanarak vidalı primer asetabular kap ile revizyon yapıldı. Femoral stemin çıkarılması sırasında komplikasyon olarak periprostetik kırık gelişti. Çimentosuz stem ve plak vida-kablo ile revize edildi $(c, d)$.
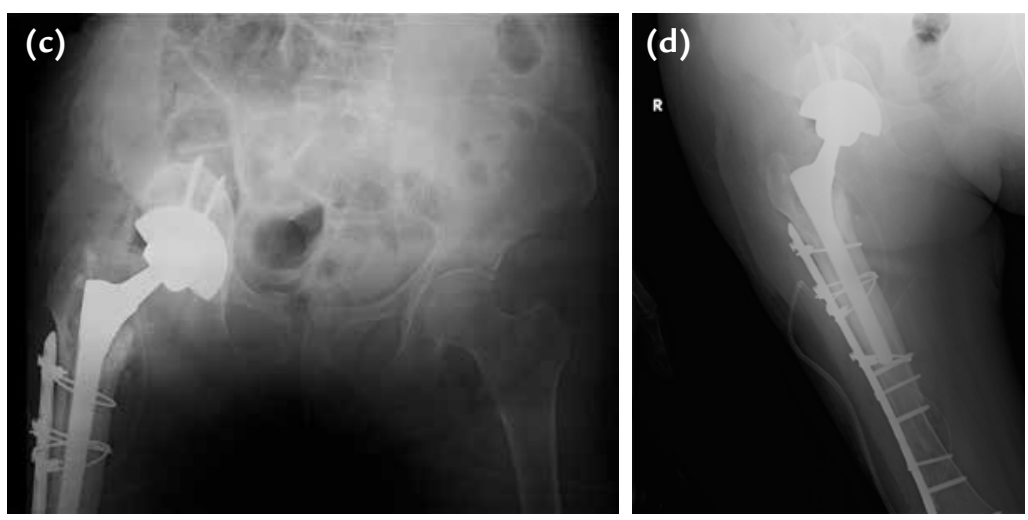

Cerrahi öncesinde ayrıntılı planlama kritiktir. Daha önceki cerrahi ile ilgili tüm bilgiler elde edilmelidir. Var olan implantla ilgili bilgiler, gerek implantın çıkarılması gerekse femoral komponentin korunması durumunda cerrah açısından önemlidir. Ayrıntılı radyolojik değerlendirme sonucunda kemik stoğunun durumuna göre spesifik protez seçenekleri ve greft ihtiyacı belirlenmelidir. Kullanılması planlanan protez için sağlam taraf üzerinde şablon çalışması yapılarak femoral offset, boyut ve kalça merkezi ile ilgili ön bilgi elde edilebilir.

\section{TEDAVi}

Etiyolojiye spesifik tedavi esas olmakla birlikte başarısız endoprotezin standart tedavisi total kalça protezidir. Femoral komponentte kötü konumlandırma veya aseptik gevşeme varlığında asetabular komponent problemi çözmeyecektir (Şekil 1). Ancak eski tip tek parça femoral komponentlerin yeni total kalça protezi sistemleri ile değiştirilmesi önerilmektedir (Şekil 2)..$^{[5]}$ Femoral komponentin uygun durumda olduğu tekrarlayan instabilite durumlarında dual-mobil asetabular bileşenler ile başarılı klinik sonuçlar elde edilebilir. ${ }^{[24]}$ 
Üç haftadan kısa süren akut enfeksiyon varlığında tek aşamalı cerrahi uygulanabilir. Yıkama ve debridmanın ardından protezin modüler komponentleri değiştirilir ve altı haftalık parenteral antibiyotik tedavisi uygulanır. Üç haftadan uzun süren kronik enfeksiyonlarda ise iki aşamalı revizyon planlanmalıdır. ilk aşamada yıkama ve debridmanın ardından protezler tamamen çıkartılır ve antibiyotikli spacer yerleştirilir. Sonrasında yine antibiyotik tedavisi verilir ve enfeksiyonun tedavi olduğundan emin olduktan sonra ikinci aşamada total kalça protezi uygulanır. İkinci aşamadan önce enfeksiyonun rezolüsyonundan emin olmak için kalça ponksiyonu yapılabilir. Morsi ve ark. başarısız endoprotez cerrahisi için bir sınıflama ve tedavi algoritması oluşturmuşlardır (Tablo 2). ${ }^{[25]}$
İleri derecede zayıf kemik stoğu, tekrarlayan enfeksiyon ve eşlik eden ciddi ek hastalık varlığında hasta için tekrar implantasyon uygun olmayabilir ve bu durumlarda son çare olarak rezeksiyon artroplastisi düşünülebilir. Yumuşak doku gevşekliğine bağlı instabilite durumunda abduktor breys tedavisi alternatif tedavi olarak uygulanabilir. Bu tedaviden yanıt alınamayan hastalarda komponent malpozisyonu dışlandıktan sonra trokanterik ilerletme ve gluteal kas transferi de etkili tedavi seçeneklerindendir. ${ }^{[26,27]}$

\section{Tedavi Sonuçları}

Endoprotezin total kalça protezine dönüştürülmesi genel olarak yüksek komplikasyon oranları ile

Tablo 2. Morsi ve ark.'nın endoprotez sınıflama sistemi ve tedavi algoritması ${ }^{[25]}$

\begin{tabular}{|c|c|c|c|c|c|c|}
\hline \multirow[b]{3}{*}{ Tip } & \multirow[b]{3}{*}{ Etiyoloji } & \multicolumn{5}{|c|}{ Revizyon yöntemi } \\
\hline & & \multirow{2}{*}{$\begin{array}{l}\text { Tek veya iki } \\
\text { aşama }\end{array}$} & \multicolumn{2}{|c|}{ Kemik grefti ihtiyacı } & \multicolumn{2}{|l|}{ Protez tipi } \\
\hline & & & Asetabulum & Femur & Asetabulum & Femur \\
\hline Tip 1 & $\begin{array}{l}\text { Asetabular problem; } \\
\text { protrüzyon ve stabil } \\
\text { femur }\end{array}$ & $\begin{array}{l}\text { Tek aşamalı } \\
\text { cerrahi }\end{array}$ & & & & \\
\hline Tip IA & $\begin{array}{l}\text { Non-modüler femoral } \\
\text { stem (Thompson, Austin } \\
\text { Moore) }\end{array}$ & & Genellikle & Bazen & $\begin{array}{l}\text { Çimentosuz } \\
\text { kap veya ring ile } \\
\text { birlikte kap }\end{array}$ & $\begin{array}{l}\text { Poroz kaplı, uzun stem } \\
\text { çimentosuz femoral } \\
\text { komponent }\end{array}$ \\
\hline Tip IB & Bipolar femoral protez & & Genellikle & Gerekli değil & $\begin{array}{l}\text { Çimentosuz } \\
\text { kap veya ring ile } \\
\text { birlikte kap }\end{array}$ & Gerekli değil \\
\hline Tip II & Femoral problem & $\begin{array}{l}\text { Tek aşamalı } \\
\text { cerrahi }\end{array}$ & & & & \\
\hline Tip IIA & $\begin{array}{l}\text { Aseptik gevşeme, kemik } \\
\text { stoğu iyi }\end{array}$ & & Gerekli değil & Gerekli değil & $\begin{array}{l}\text { Çimentolu/ } \\
\text { Çimentosuz kap }\end{array}$ & Standart femoral protez \\
\hline Tip IIB & $\begin{array}{l}\text { Aseptik gevşeme, kemik } \\
\text { stoğu iyi değil }\end{array}$ & & Gerekli değil & Genellikle & $\begin{array}{l}\text { Çimentolu/ } \\
\text { Çimentosuz kap }\end{array}$ & $\begin{array}{l}\text { Poroz kaplı, uzun stem } \\
\text { çimentosuz femoral } \\
\text { komponent }\end{array}$ \\
\hline Tip IIC & Periprostetik kırık & & Gerekli değil & Bazen & $\begin{array}{l}\text { Çimentolu/ } \\
\text { Çimentosuz kap }\end{array}$ & $\begin{array}{l}\text { Poroz kaplı, uzun stem } \\
\text { çimentosuz femoral } \\
\text { komponent }\end{array}$ \\
\hline Tip III & $\begin{array}{l}\text { Tip I ve II'deki asetabular } \\
\text { ve femoral problemlerin } \\
\text { çeşitli kombinasyonları }\end{array}$ & $\begin{array}{l}\text { Tek aşamalı } \\
\text { cerrahi }\end{array}$ & $\begin{array}{l}\text { Tip I ve II olduğu } \\
\text { gibi etiyolojiye } \\
\text { göre tedavi }\end{array}$ & & & \\
\hline Tip IV & $\begin{array}{l}\text { Instabilite ve tekrarlayıcı } \\
\text { dislokasyon }\end{array}$ & $\begin{array}{l}\text { Tek aşamalı } \\
\text { cerrahi }\end{array}$ & Gerekli değil & Bazen & $\begin{array}{l}\text { Çimentolu/ } \\
\text { Çimentosuz kap }\end{array}$ & $\begin{array}{l}\text { Poroz kaplı, uzun stem } \\
\text { çimentosuz femoral } \\
\text { komponent }\end{array}$ \\
\hline Tip V & Enfeksiyon & $\begin{array}{l}\text { İki aşamalı } \\
\text { cerrahi }\end{array}$ & & & & \\
\hline
\end{tabular}


ilişkilidir. Warwick ve ark. ${ }^{[28]}$, revizyon endoprotez cerrahisinde \%64 oranda majör ameliyat içi veya sonrası komplikasyon, Sierra ve Cabanela ${ }^{[29]}$ ise $\% 45$ oranında cerrahi sürecinde komplikasyon bildirmişlerdir. Hernandez ve ark., endoprotezlerin total kalça protezine dönüştürülmesini primer ve revizyon total kalça protezleri ile karşılaştırmıştır. Bu çalışmaya göre 2000-2014 arası hastalar değerlendirildiğinde endoprotez sonrası total kalça protezi uygulamasının primer total kalça protezine kıyasla daha yüksek oranda komplikasyon, tekrar cerrahi ve periprostetik kırıkla ilişkili olduğu belirlenmiştir. Ayrıca endoprotez sonrası total kalça protezi uygulaması, revizyon total kalça protezi ile karşılaştırıldığında daha yüksek oranda periprostetik kırık ve tekrar cerrahi oranları ile ilişkili bulunmuştur. ${ }^{[30]}$

\section{SONUÇ}

Yaşıılarda kalça kırığına yönelik endoprotez uygulaması sonrası revizyon cerrahisi, yönetimi oldukça zorlu majör bir ortopedik cerrahidir. Bu özel yaş grubunda çoğu kez eşlik eden sistemik hastalıkların varlığı ve azalmış kemik kalitesi revizyon cerrahisini güçleştirmektedir. Revizyon cerrahisinin komplikasyon oranları yüksek olsa da tedavi neticesinde birincil amaç olan hastanın en kısa sürede hareketini kazanması ve önceki aktivite seviyesine ulaşması başarılabilir. Başarıda sistematik bir değerlendirme ile etiyolojinin doğru saptanması ve buna yönelik tedavi uygulanması en önemli noktadır.

\section{KAYNAKLAR}

1. Schmidt $\mathrm{AH}$, Swiontkowski MF. Femoral neck fractures. Orthop Clin North Am 2002;33(1):97-111, viii. Crossref

2. Gao H, Liu Z, Xing D, Gong M. Which is the best alternative for displaced femoral neck fractures in the elderly?: A metaanalysis. Clin Orthop Relat Res 2012;470(6):1782-91. Crossref

3. Bhandari M, Devereaux PJ, Einhorn TA, Thabane L, Schemitsch EH, Koval KJ, Frihagen F, Poolman RW, Tetsworth K, Guerra-Farfán E, Madden K, Sprague S, Guyatt G; HEALTH Investigators. Hip fracture evaluation with alternatives of total hip arthroplasty versus hemiarthroplasty (HEALTH): protocol for a multicentre randomised trial. BMJ Open 2015;5(2):e006263. Crossref

4. Liu Y, Tao X, Wang P, Zhang Z, Zhang W, Qi Q. Metaanalysis of randomised controlled trials comparing unipolar with bipolar hemiarthroplasty for displaced femoral-neck fractures. Int Orthop 2014;38(8):1691-6. Crossref

5. Sheth NP, Dattilo JR, Schwarzkopf R. Evaluation and Management of Failed Hemiarthroplasty. J Am Acad Orthop Surg 2018;26(20):717-26. Crossref

6. Tidermark J, Ponzer S, Svensson O, Söderqvist A, Törnkvist $\mathrm{H}$. Internal fixation compared with total hip replacement for displaced femoral neck fractures in the elderly. A randomised, controlled trial. J Bone Joint Surg Br 2003;85(3):380-8. Crossref
7. Rogmark C, Johnell O. Primary arthroplasty is better than internal fixation of displaced femoral neck fractures: a metaanalysis of 14 randomized studies with 2,289 patients. Acta Orthop 2006;77(3):359-67. Crossref

8. Noailles T, Brulefert K, Chalopin A, Longis PM, Gouin F. What are the risk factors for post-operative infection after hip hemiarthroplasty? Systematic review of literature. Int Orthop 2016;40(9):1843-8. Crossref

9. Tsai $\mathrm{CH}$, Muo $\mathrm{CH}$, Hung $\mathrm{CH}$, Lin $\mathrm{TL}$, Wang $\mathrm{TI}$, Fong $\mathrm{YC}$, Hsu HC. Disorder-related risk factors for revision total hip arthroplasty after hip hemiarthroplasty in displaced femoral neck fracture patients: a nationwide population-based cohort study. J Orthop Surg Res 2016;11(1):66. Crossref

10. van den Bekerom MP, Sierevelt IN, Bonke $H$, Raaymakers EL. The natural history of the hemiarthroplasty for displaced intracapsular femoral neck fractures. Acta Orthop 2013;84(6):555-60. Crossref

11. Phillips TW. Thompson hemiarthroplasty and acetabular erosion. J Bone Joint Surg Am 1989;71(6):913-7. Crossref

12. Li T, Zhuang $Q$, Weng $X$, Zhou L, Bian Y. Cemented versus uncemented hemiarthroplasty for femoral neck fractures in elderly patients: A meta-analysis. PLoS One 2013;8(7):e68903. Crossref

13. Gjertsen JE, Lie SA, Vinje T, Engesæter LB, Hallan G, Matre $\mathrm{K}$, Furnes $\mathrm{O}$. More re-operations after uncemented than cemented hemiarthroplasty used in the treatment of displaced fractures of the femoral neck: an observational study of 11,116 hemiarthroplasties from a national register. J Bone Joint Surg Br 2012;94(8):1113-9. Crossref

14. Florschutz AV, Langford JR, Haidukewych GJ, Koval KJ. Femoral neck fractures: Current management. J Orthop Trauma 2015;29(3):121-9. Crossref

15. Pajarinen J, Savolainen V, Tulikoura I, Lindahl J, Hirvensalo E. Factors predisposing to dislocation of the Thompson hemiarthroplasty: 22 dislocations in 338 patients. Acta Orthop Scand 2003;74(1):45-8. Crossref

16. Blewitt N, Mortimore S. Outcome of dislocation after hemiarthroplasty for fractured neck of the femur. Injury 1992;23(5):320-2. Crossref

17. Zhou Z, Yan F, Sha W, Wang L, Zhang X. Unipolar versus bipolar hemiarthroplasty for displaced femoral neck fractures in elderly patients. Orthopedics 2015;38(11):697-702. Crossref

18. Kwok DC, Cruess RL. A retrospective study of Moore and Thompson hemiarthroplasty: A review of 599 surgical cases and an analysis of the technical complications. Clin Orthop Relat Res 1982;(169):179-85. Crossref

19. Ninh CC, Sethi A, Hatahet M, Les C, Morandi M, Vaidya R. Hip dislocation after modular unipolar hemiarthroplasty. J Arthroplasty 2009;24(5):768-74. Crossref

20. Maheshwari R, Kumar PN, Matthews JG. Unstable hemiarthroplasty of the hiptreated with a simple technique of acetabular augmentation. J Arthroplasty 2007;22(2):231-4. Crossref

21. Parvizi J, Gehrke T; International Consensus Group on Periprosthetic Joint Infection. Definition of periprosthetic joint infection. J Arthroplasty 2014;29(7):1331. Crossref

22. Yoon BH, Lee YK, Jo WL, Ha YC, Choi DH, Koo KH. Incidence and risk period of periprosthetic femoral fracture after cementless bipolar hemiarthroplasty in elderly patients. J Arthroplasty 2016;31(6):1326-30. Crossref

23. Yasen AT, Haddad FS. Periprosthetic fractures: bespoke solutions. Bone Joint J 2014;96-B(11 Supple A):48-55. Crossref 
24. Carulli C, Macera A, Matassi F, Civinini R, Innocenti M. The use of a dual mobility cup in the management of recurrent dislocations of hip hemiarthroplasty. J Orthop Traumatol 2016;17(2):131-6. Crossref

25. Morsi E, Habib ME, Elseedy A, Eid T. Revision of failed hip hemiarthroplasty. Classification, management, and followup. J Orthop 2016;13(2):63-8. Crossref

26. Ekelund A. Trochanteric osteotomy for recurrent dislocation of total hip arthroplasty. J Arthroplasty 1993;8(6):629-32. Crossref

27. Whiteside LA. Surgical technique: Gluteus maximus and tensor fascia lata transfer for primary deficiency of the abductors of the hip. Clin Orthop Relat Res 2014;472(2):645-53. Crossref
28. Warwick D, Hubble M, Sarris I, Strange J. Revision of failed hemiarthroplasty for fractures at the hip. Int Orthop 1998;22(3):165-8. Crossref

29. Sierra RJ, Cabanela ME. Conversion of failed hip hemiarthroplasties after femoral neck fractures. Clin Orthop Relat Res 2002;(339):129-39. Crossref

30. Hernandez NM, Fruth KM, Larson DR, Kremers HM, Sierra RJ. Conversion of Hemiarthroplasty to THA Carries an Increased Risk of Reoperation Compared with Primary and Revision THA. Clin Orthop Relat Res 2019;477(6):1392-9. Crossref 